\title{
Digital Technologies, as a Factor in the Search for a New Quality of Inclusive Education.
}

\author{
Daniil Yaskevich ${ }^{1, *}$ \\ ${ }^{1}$ Southern Federal University, Rostov-on-Don, Russian Federation
}

\begin{abstract}
More than a billion people in the world have disabilities, and therefore face barriers in various areas of life. Digital technologies in inclusive education can help integrate these people into the active social and economic life of society. The purpose of this study was to analyze new educational technologies from the point of view of providing a new level of inclusive education. This article analyzes and presents visual graphs on the number of people with disabilities, their involvement in the higher education system of the Russian Federation, regulatory documents relating to people with disabilities and inclusive education. Studied the problems that arise in people with disabilities. Personal and professional requirements for teachers are formulated. An analysis of the requirements for educational institutions in the context of teaching people with disabilities was carried out, digital technologies and additional tools used in inclusive education, as well as the tasks they perform, the experience of implementing inclusive education and digital technologies in this area were analyzed. This article also proposes the concept of the Center for the Education of Persons with Disabilities under the President of the Russian Federation, the purpose of which is to implement the principles of humanism and economic expediency by developing the prospects of persons with disabilities with its further application. The main tasks of the Center are: modernization of the inclusive education system, modernization of the regulatory framework with the involvement of persons with disabilities, selection and special training of domestic teachers, attraction of a foreign professor-teacher for the development of inclusive education, involvement of Russian-speaking students in the Russian education system, regardless of citizenship, temporarily or permanently living abroad, stable stereotypes in a society with limited physical abilities, as limited, but not limited in the realization of oneself as a full-fledged member of society.
\end{abstract}

\section{Introduction}

According to the UN data on disability (World report on disability. 2011), more than a billion people, or about $15 \%$ of the world's population, are disabled, almost 200 million experience serious difficulties in functioning. In the Russian Federation, according to the FRI (Federal Register of Disabled Persons) report, as of (01.02.2021), there are less than 11 million $(10,877,073)$ people, which is approximately $7.5 \%$ of the population of Russia, of which

\footnotetext{
*Corresponding author: daniil3008@gmail.com
} 
over 700 thousand are children, and this is growing. All over the world, people with disabilities face barriers, obstacles to the education of their achievements in the field of economic and financial indicators, social activity. Also, persons with disabilities (hereinafter referred to as persons with disabilities) experience difficulties in obtaining basic benefits such as education, health care, employment, as well as information and communication. The international community, including the Russian Federation, recognizes the urgency of this problem by developing appropriate programs and regulations, supporting support, adaptation and integration of people with disabilities. The main international document regulating the rights of people with disabilities is the "Convention on the Rights of Persons with Disabilities" adopted by a resolution of the UN Council in (2006) Russia ratified the UN Convention on the Rights of Persons with Disabilities in (2012).

According to the principles of humanism enshrined in Article 43 of the Constitution of the Russian Federation (as amended on December 30, 2008, February 5, July 21, 2014, March 14, 2020), which states that:

"Item 1. Everyone has the right to education."

"Clause 3. Everyone has the right, on a competitive basis, to get a higher education free of charge in a state or municipal educational institution and at an enterprise.", High-quality public education is one of the fundamental rights of citizens.

Education is one of the main factors in improving social adaptation and financial wellbeing. Professional education, in turn, influences the successful integration of young people. Upon receiving professional education and further employment, limited liability persons have a real opportunity to improve both the material level and social status, integrating into the life of society, developing new motivations and new forms of social activity. [9]

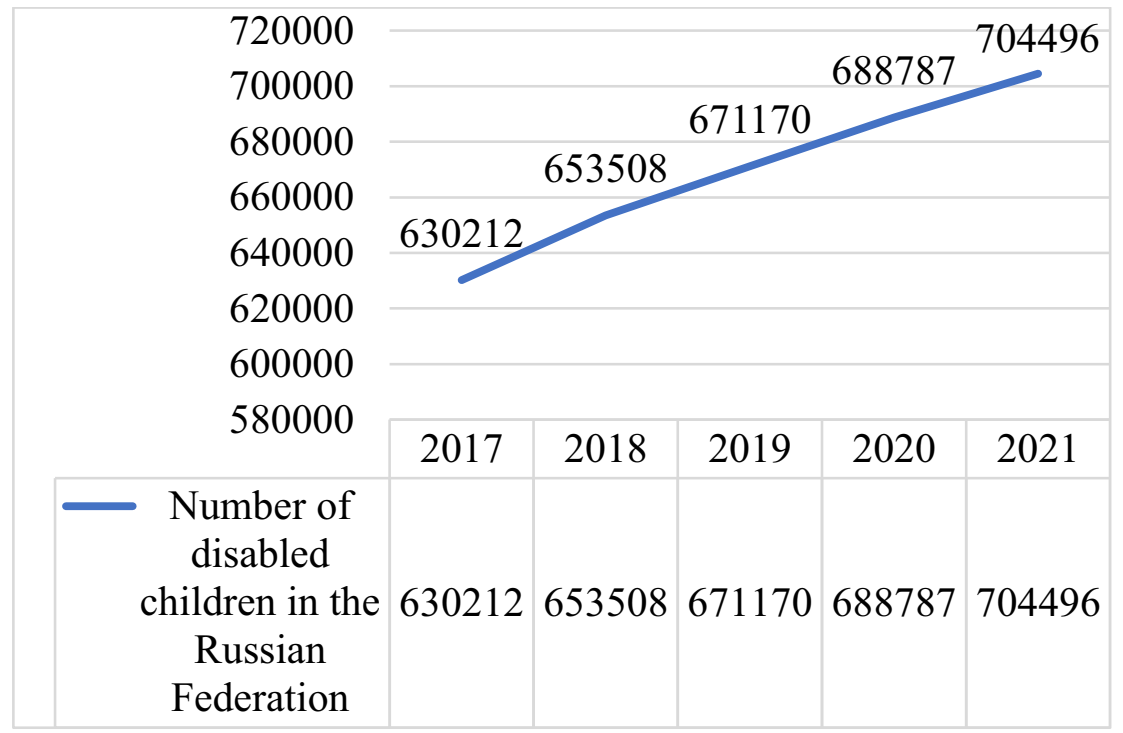

Fig. 1. The number of disabled children in Russian Federation 


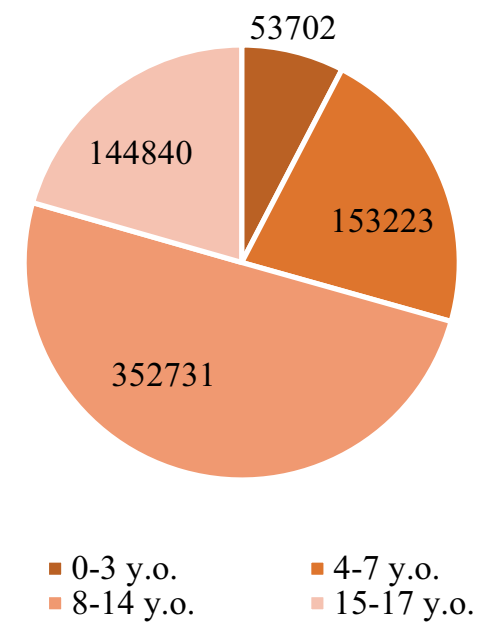

Fig. 2. Distribution of disabled children by age in the Russian Federation

About 145 thousand people are disabled children aged 15-17, future potential students, however, according to the Rosstat report "Selective observation of the quality and availability of services in education, health care and social services, promoting employment of the population" less than $30 \%$ of people with disabilities have the opportunity get a new profession.

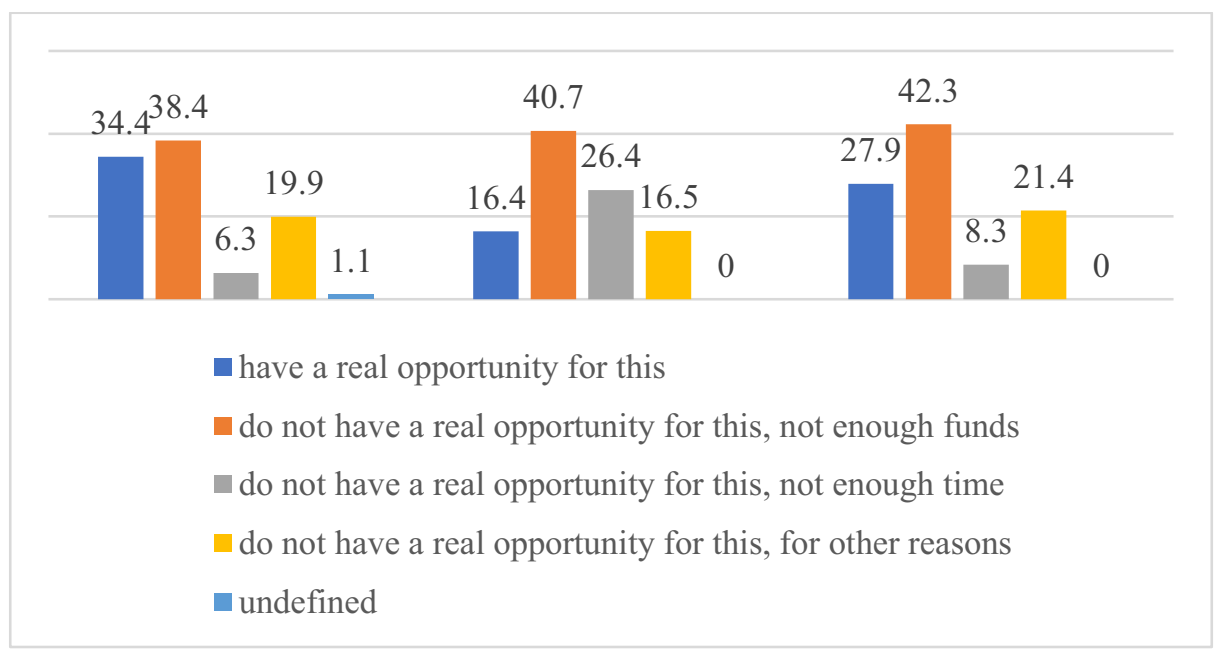

Fig. 3. Distribution of persons with disabilities according to the availability of a real opportunity to get a new profession(percentage).

According to the Rosstat report "Structure of persons aged 15 and older with disabilities, by educational level" less than $13 \%$ of persons with disabilities have a higher education, while the general level is approximately $27 \%$, i.e. higher education is more than twice as widespread as among people with disabilities. 


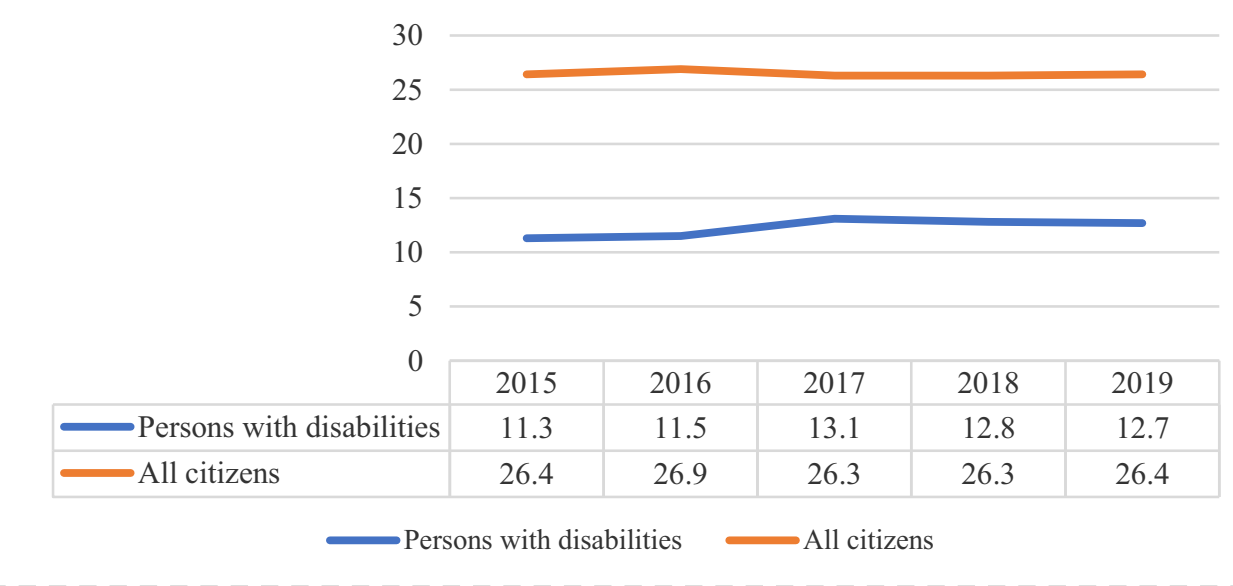

Fig. 4. The structure of citizens by education level (percentage).

One way to improve this situation is inclusive education. Inclusive education is the provision of equal access to education for all students, pay attention to the diversity of special educational needs and individual opportunities [2].

The main goal of inclusive education is to create an adapted and environmentally friendly information and social environment.

The information environment means a set of factors that are designed to form the activity of persons with disabilities in learning, through information and communication technologies in the process of information interaction with the teacher with the effective use of all components of the educational environment. Activities with each component of the educational environment are carried out using information and communication technologies. It is worth pointing out that the main condition of the environment is information interaction between persons using interactive ICTs. The collection of hardware and systems, digital means is an integral part of information training for people with disabilities. The specificity of modern inclusive education lies in the wider use of information and communication tools in the study of educational material, which imitate individual functions of the teacher (S. Dukuzumuremi [6], Adriana G [2], S.N. Kerkhoff [7], P.-A Chinkvin [5]) The purpose of this study was to analyze new educational technologies in terms of providing a new level of inclusive education and developing a system that allows the maximum development of the potential of people with disabilities and its further implementation. In this regard, the tasks were set to assess the problems of persons with disabilities in education, the potential of digital technologies to solve them and increase the level of inclusive education.

\section{Materials and methods}

The main theoretical research methods were comparative and structural analysis, classification and systematization, multilevel modeling. The study analyzed the world and Russian statistics on the number of children with disabilities, their level of education, access to higher education, the difficulties faced by persons with disabilities in obtaining education, regulatory documents that ensure this activity, experience in the implementation of inclusive education and digital technologies in this area on the example of works by such authors as: G. Shumsky [14], A. Morina [10, 11], L.M. Banks [3], D. Robinson [13], Pinazo E. P.[12] and others. 


\section{Results}

Problems of persons with disabilities.

Based on the works of E.M. Unianu [15], G. Shumsky [14], the main problems of persons with disabilities were identified:

Ineffective solutions in support policies and programs. When developing standards and support programs, the needs of people with disabilities are not always pay attention to opinion of people with disabilities, or existing ones are not applied in practice. The most common deficiencies in education policy include the lack of financial and other targeted incentives for persons with disabilities to attend educational institutions, as well as a lack of services in the field of social protection and education.

Bias. Prejudice contributes to the creation of barriers to education, communication, and, as a result, participation in the social life of society.

Difficulties in obtaining information and communication. There is little information in the formats accessible to people with disabilities (blind, visually impaired, deaf and hard of hearing, etc.), and the information needs of people with disabilities are not met. People with disabilities use information and communication technologies much less than non-disabled people. In some cases, they may not even have access to basic digital products and services. Problems in interacting with other people, often the social circle of people with disabilities is more like a point (family, social and medical workers)

Infrastructure inaccessibility. Many buildings and transport systems are not adapted for people with disabilities. There are no special devices and objects that allow you to get anywhere, climb stairs, cross the road, and more. Lack of the ability to interact with most objects (such as ATMs, information stands, etc.). Lack of access to transport and infrastructure is a common factor for people with disabilities, which is a reason for refusing to look for work and restricting access to education.

Low achievement in education. According to the Federal State Statistics Service for 20152020. only half of incoming students with disabilities cope with educational programs and graduate. In addition, the share of graduates working in their specialty is also low. Also, in the work of Aldosiry N. [1] the school it is indicated that disabled people cope with the modern education system very hard.

Reduced economic activity. Among people with disabilities, the number of unemployed is higher and the average income is lower than among other citizens. On average, the employment rate among disabled people is almost half (44\%) than among non-disabled people.

Personal and professional requirements for teachers:

Based on the works of P.-A. Chinqin, P. Gitton, H. Sozeon [5], D. Bjekić [4], Mara D. [8] formulated the requirements for teachers, their personal qualities and professional skills necessary for developing activities for children with disabilities.

The professional requirements for a teacher working in an inclusive education system can be grouped into three main groups:

1. General civil qualities that are inherent in all representatives of professions related to working with people, first of all, the adoption of children, regardless of the level of educational opportunities, behavioral characteristics, state of psychological and physical health;

2. Qualities that determine the specifics of the teacher's work in the system of inclusive education, for example:

- High communication skills with children;

- Ability to form the emotionally integral sphere of the child, through the design of various situations and events; 
- Skills of building educational activities taking into account cultural differences, individual needs, gender and age differences, maintaining a friendly business atmosphere among children;

- Ability to draw up a program together with other specialists and monitor the dynamics of development, according to this program;

- Own inclusive psychological and pedagogical technologies;

3. Special knowledge, skills and abilities that provide a corrective orientation of the development, upbringing, learning processes caused by a complex structure of disorders in the development of a child, including special knowledge in the field of anatomy, physiology, social psychology, defectology and social work, skills in providing assistance any child, the ability to identify various problems associated with the peculiarities of development, the environment in the team, inclusion in the team.

Requirements for educational institutions of the Russian Federation in accordance with: "SP 31-102-99 Requirements for the accessibility of public buildings and structures for people with disabilities and other low-mobility visitors":

The educational process for receiving education by students with disabilities and disabled people is carried out in all buildings, which have:

4. Availability of material and technical support for educational activities;

5. Availability of conditions for the protection of the health of students;

6. Entrances equipped with ramps and a bell to the guard on duty;

7. Dormitories located within walking distance from the educational building;

8. Accessibility of the adjacent territory;

9. Availability of specially equipped sanitary and hygienic facilities;

10. Equipping with fire-prevention sound and light alarms;

11. There is a parking lot for people with disabilities and disabled people;

12. In lecture halls, laboratories, a library and other premises, there are places for students for each type of health disorder - musculoskeletal system, hearing and vision.

Within the framework of the federal state program "Accessible Environment" for 20112015, approved in 2012, provided for measures to equip ordinary educational institutions with special equipment and devices for unhindered access to the premises and education of disabled children, including those with visual impairments, hearing impairments, and musculoskeletal disorders. However, the implementation of this program in educational institutions is carried out slowly and unproductively, which, in our opinion, is associated with a number of reasons, including significant material and financial costs, historical buildings, building density, etc.

Digital educational technologies in inclusive education:

- Various platforms suitable for distance education (such as MS Teams, Zoom, etc.), which allow teacher-student interaction regardless of the location of the subjects, have been massively tested in the field of education during the pandemic;

- Various types of MOOCs;

- Electronic library funds (with the ability to use related devices);

- Platforms for the exchange of knowledge between students;

- Programs leading training in a game format;

- Interactive programs that ensure the receipt and transmission of information in the format that is comfortable for the teacher, student (translation from one type of information to another) using various additional devices:

For the deaf or hard of hearing: Videophone, sign language interpreters, etc;

For the blind: Braille display, speech synthesizers, Braille e-book, audio systems, etc;

For persons with musculoskeletal disorders: Adapted keyboards, computer joysticks, tablets, etc.

Digital technologies allow: 
1. To simplify the preparation of individual programs for students in accordance with their capabilities;

2. The ability for students to carry out the study load within the permissible load;

3. Teach as adapted as possible in relation to limitations depending on pathologies;

4. To attract teachers with a predisposition and special skills to work with people with disabilities;

5. Reduce the burden on educational institutions for preparing buildings for teaching this category of students;

6. Expand the range of available educational programs and educational institutions;

7. Teach using the languages and methods and methods of communication most appropriate for the individual and in an environment that maximizes learning and social development.

Further integration of digital technologies into the system of inclusive education will increase the level of education by:

1. Increasing the interactivity of the educational process;

2. Obtaining knowledge from the best teachers in their field;

3. Improving the environmental friendliness of the educational environment;

4. Expansion of available and creation of new teaching methods.

\section{Discussion}

One of the ways of realizing the right of persons with disabilities to a quality higher education, in the author's opinion, is the creation of a state Center for the education of persons with disabilities under the President of the Russian Federation, as the main guarantor of the implementation of the constitutional rights of citizens, the goals of which are:

Implementation of the principles of humanism and economic feasibility by maximizing the potential of people with disabilities with its further application;

Full involvement of persons with disabilities in the social and economic activities of the state as active and loyal members of society.

The main tasks of this Center:

1. Modernization of the system of inclusive education;

2. Methodological and technical developments in the field of inclusive education;

3. Modernization of the legal and regulatory framework for persons with disabilities;

4. Creation of a high-quality teaching staff, capable of working with people with disabilities, through special training of domestic teachers, attracting foreign teaching staff for the development of inclusive education;

5. Involvement in the Russian education system of Russian-speaking students, regardless of citizenship, temporarily or permanently residing abroad;

6. Formation of a stable stereotype in society of perception of people with disabilities as physically challenged, but not having limitations in the realization of themselves as a fullfledged member of society.

Functions of the Center:

1. Development of new and adaptation of existing information and digital products and technologies, as well as their introduction into the system of inclusive education.

2. Development of teaching methods using the above technologies and in accordance with the objective needs and capabilities of persons with disabilities within the framework of the existing, approved by the Ministry of Education, curricula for the relevant specialties.

3. Development, based on domestic resources and technologies, a single digital platform that provides:

4. Inclusive education (with the possibility of training foreign students, as well as students who are unable to obtain a higher education (due to remoteness, financial condition, etc.) 
5. Communication of persons with disabilities with each other, with educational organizations and state and executive authorities, with the support and assistance of this Center

6. Development of selection criteria, selection and special training of the teaching staff.

7. Development and coordination of the structure of interaction with relevant ministries and departments, other institutions and organizations of all forms of ownership and between them within the framework of the program.

8. Analysis of the labor market in the context of employment of persons with disabilities

9. Development and adaptation of testing and vocational guidance systems in accordance with the data obtained

10. Assistance in employment in organizations and institutions of all forms of ownership

11. Assistance in solving organizational issues that impede the access of persons with disabilities to training within the framework of this program

12. Development and coordination with specialized structures of the possibility of obtaining a state diploma by persons with disabilities within the framework of the proposed systemic training in accordance with existing and approved specialties.

To fulfill its mission, the Center must have the right to:

1. Direct appeal to state and executive authorities.

2. Development, coordination and participation in the discussion of any legislative initiatives related to HIA.

3. Funding initially from the state, regional and local budgets, specialized organizations, but in the future, it is possible to attract funds from various grants, funds received from the implementation of projects with the participation of this platform and the provision of paid educational services to foreign students.

\section{Conclusions}

Lots of people are people with disabilities who have barriers to self-realization and active socio-economic life, such as ineffective decisions in policies and support programs, prejudice, difficulties in obtaining information and communication, infrastructural inaccessibility, low educational achievements, reduced economic activity. Problems in obtaining higher education for people with disabilities are associated not only with their special needs, but also with high requirements for teachers and educational institutions, which are not met at a sufficient level. The development of new educational technologies and methods can reduce the gap between persons with disabilities and other participants in the educational environment, reduce the burden on teachers and educational institutions, which will improve the efficiency of the educational process. In addition to the educational function (which is their legal right), inclusive education allows people with disabilities to adapt and socialize. Obtaining an equal level of education increases competitiveness in the labor market in the future, which enables people to be full-fledged participants in society. Digital technologies provide a favorable environment for adaptation and introduction of persons with disabilities into society, as equal participants in any sphere of life, and allows them to make the life of these people more fulfilling. However, to achieve this, an adapted educational environment, the development of individual programs and the active introduction of new educational technologies are required. The creation of such an environment can be achieved by the implementation of the Center for the Education of Persons with Disabilities under the President of the Russian Federation, which takes on the responsibility of implementing the principles of humanism and economic feasibility by maximizing the potential of persons with disabilities with its further use, in the form of full involvement of persons with disabilities in social economic activity of the state as active and loyal members of society, which allows obtaining from people in need of state assistance, active, self-sufficient, qualified and loyal citizens. 


\section{References}

1. N. Aldosiry, A.A. Alharbi, R. Alrusaiyes, Practices to prepare students with disabilities for the transition to new educational settings. Children and Youth Services Review, 120, 33-38 (2021)

2. A.G. Alves, A.E.F. Schmidt, K.D.P. Carthcat, R.C.L. Hostins, Exploring Technological Innovation towards Inclusive Education: Building Digital Games - An Interdisciplinary Challenge. Social and Behavioral Sciences, 174, 3081-3086 (2015)

3. L.M. Banks, C. Davey, T. Shakespeare, H. Kuper, Disability-inclusive responses to COVID-19: Lessons learned from research on social protection in low- and middleincome countries. World Development, 137, 101-117 (2021)

4. D. Bjekić, S. Obradović, M. Vučetić, M. Bojović, E-teacher in Inclusive e-education for Students with Specific Learning Disabilities. Social and Behavioral Sciences, 128, 128133 (2014)

5. P.-A., Cinquin, P. Guitton, H. Sauzéon, Online e-learning and cognitive disabilities: A systematic review. Computers \& Education, 130, 152-167 (2019)

6. S. Dukuzumuremyi, P. Siklander, Interactions between pupils and their teacher in collaborative and technology-enhanced learning settings in the inclusive classroom. Teaching and Teacher Education, 76, 165-174 (2018)

7. S.N. Kerkhoff, M.E. Cloud, Equipping teachers with globally competent practices: A mixed methods study on integrating global competence and teacher education. International Journal of Educational Research, 103 (2020)

8. D. Mara, Higher Education for People with Disabilities - Romanian Education Experience. Social and Behavioral Sciences, 142, 78-82 (2014)

9. S. Marimuthu, L.S. Cheong, Inclusive Education for Social Transformation. Social and Behavioral Sciences, 172, 317-322 (2015)

10. Moriña, M. D. Cortés-Vega, V.M. Molina, What if we could imagine the ideal faculty? Proposals for improvement by university students with disabilities. Teaching and Teacher Education, 52, 91-98 (2015)

11. I. O. Moriña, Planning and implementing actions for students with disabilities: Recommendations from faculty members who engage in inclusive pedagogy. International Journal of Educational Research, 103, 98-111 (2020)

12. E. P. Pinazo, M. C. Reina, A model to Enhance Interaction for People with Severe Intellectual Disability in Healthcare, Education and Interpreting. Social and Behavioral Sciences, 237, 1189-1195 (2017)

13. D. Robinson, Effective inclusive teacher education for special educational needs and disabilities: Some more thoughts on the way forward. Teaching and Teacher Education, 61, 164-178 (2017)

14. G. Szumski, J. Smogorzewska, P. Grygiel, Attitudes of students toward people with disabilities, moral identity and inclusive education - A two-level analysis, Research in Developmental Disabilities, 102, 103685 (2020)

15. E. M. Unianu, Teachers' Perception, Knowledge and Behavior in Inclusive Education. Social and Behavioral Sciences, 84, 1237-1241 (2013) 